\title{
Psychometric properties of the Physical Activity Scale for the Elderly in Chinese patients with COPD
}

This article was published in the following Dove Press journal:

International Journal of COPD

22 December 2016

Number of times this article has been viewed

Yan-xia Tao, ${ }^{1, *}$ Lan Wang, ${ }^{1, *}$ Xiao-yan Dong,' Hong Zheng, ${ }^{2}$ Ya-shu Zheng, ${ }^{2}$ Xing-yue Tang, 'Yue Zhao,' Qing Zhang'

'School of Nursing, Tianjin Medical University, ${ }^{2}$ Department of

Respiratory Care, Tianjin First Center Hospital, Tianjin, People's Republic of China

*These authors contributed equally to this work

Video abstract

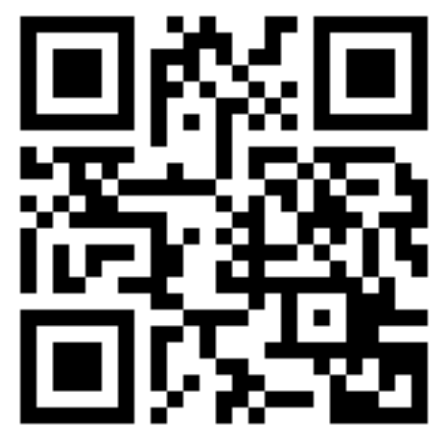

Point your SmartPhone at the code above. If you have a QR code reader the video abstract will appear. Or use: http://youtu.be/Vv6ALAv6KzO

Correspondence: Yue Zhao; Qing Zhang School of Nursing, Tianjin Medical University, 22 Qi Xiang Tai Road, Heping District, Tianjin 300070,

People's Republic of China

Tel +862283336901

$+8602283336907$

Fax +862283336900

Email yuezhao35@hotmail.com; snzhangqing@।26.com
Background: For patients with COPD, physical activity (PA) is recommended as the core component of pulmonary rehabilitation, but there is lack of a validated questionnaire for assessing the PA effectively.

Aim: To evaluate the reliability and validity of the Chinese version of Physical Activity Scale for the Elderly (PASE-C) in patients with COPD.

Methods: A cross-sectional study was conducted with 167 outpatients aged 60 years or older with COPD. Test-retest reliability and internal consistency were calculated by intraclass correlation coefficient (ICC) and Cronbach's coefficient $\alpha$, respectively. Validity was evaluated by correlation with the International Physical Activity Questionnaire-Short (IPAQ-S), data of pedometer, Self-Efficacy for Managing Chronic Disease 6-Item Scale (SES6), Hospital Anxiety and Depression Scale (HADS), Medical Outcomes Study 36-Item Short Form Health Survey (SF-36), grip strength, and disease characteristics.

Results: The PASE-C had an excellent seven-day test-retest reliability $(\mathrm{ICC}=0.98)$ and an acceptable internal consistency (Cronbach's $\alpha=0.71$ ). The content validity was supported by an item-content validity index, a scale-content validity index/universal agreement, and a scale-content validity index/average value of $0.70-1,0.70$, and 0.93 , respectively. Concurrent validity was tested by correlation with IPAQ-S ( $r=0.651)$. Criterion validity was confirmed by correlation with the walking steps $(r=0.611)$ and energy expenditure $(r=0.493)$. For construct validity, PASE-C had correlations with SES6 $(r=0.396)$, HADS for depression $(r=-0.234)$, seven subscales of SF-36 $(r=0.182-0.525)$, grip strength $(r=0.341)$, and disease characteristics including the duration of COPD ( $r=-0.215)$, modified British Medical Research Council scale ( $r=-0.354)$, forced expiratory volume in one second as percentage of predicted $(r=0.307)$, and Global Initiative for Chronic Obstructive Lung Disease grade ( $r=-0.264$ ), with a good construct validity (all $P<0.05$ ).

Conclusion: The PASE-C has acceptable reliability and validity for patients aged 60 years or older with COPD, and it can be used as a valid tool to measure the PA of patients with COPD in the People's Republic of China.

Keywords: Physical Activity Scale for the Elderly, COPD, reliability, validity, physical activity, elderly

\section{Introduction}

Physical activity (PA) is essential to maintain health in healthy and elderly people, especially in patients with chronic conditions. ${ }^{1}$ PA makes its effect on patients through physiological and psychological mechanisms, such as fall of blood pressure and improvement of depression and anxiety. ${ }^{2}$ Patients with COPD are commonly found to be physically inactive, compared with healthy subjects. ${ }^{3}$ 
Long-term difficulty in breathing reduces exercise ability in patients with COPD leading them to perform only their regular activity, ${ }^{4}$ and the prevalence of physical inactivity increases with the severity of COPD. ${ }^{5,6}$ COPD was recently characterized as a preventable and treatable disease, with significant systemic consequences. ${ }^{7,8}$

However, physical inactivity is considered to be causing the systemic consequences of COPD, ${ }^{9}$ such as osteoporosis, weakness of skeletal muscle, and cardiovascular diseases. ${ }^{10}$ In addition, physical inactivity would increase the rate of hospital admission, ${ }^{11}$ and lead to decline in lung function. ${ }^{12}$ A previous epidemiologic study showed that physical inactivity is positively associated with the mortality of patients with COPD. ${ }^{11} \mathrm{PA}$ and self-efficacy are the core components of pulmonary rehabilitation. ${ }^{13,14} \mathrm{PA}$ is associated with selfefficacy, and increasing PA is related to improvements in psychological functioning and quality of life. . $^{11,15,16}$

Recently, an increasing number of studies have focused on the effects of PA, screening of physical inactivity, and interventions for increasing PA, aimed to promote the development of recommendations that insist PA requirements to be taken into account for patients with COPD. ${ }^{17,18}$ However, there is lack of specific tools for an effective and quick assessment of PA in patients with COPD. ${ }^{19}$ Obviously, finding a reliable and valid tool to assess PA in patients with COPD is the first and crucial step for further study.

There are two different approaches for assessing PA: objective approach including accelerometers and pedometers, and subjective approach mainly including questionnaires. Although objective approach can provide more precise measurements and is widely used for quantifying PA, compared with questionnaires, it is less practical to be used in clinical settings and is unable to distinguish different domain-specific activities. ${ }^{20}$ Otherwise, questionnaires are inexpensive and not reactive to respondent's behavior, ${ }^{21}$ and are being widely applied in large-scale studies. ${ }^{22}$

Recently, a systematic review showed that there were 13 PA questionnaires for the elderly until 2009, among which only three showed good reliability, including Physical Activity Scale for the Elderly (PASE). Compared with the two other questionnaires, PASE also showed good validity. ${ }^{23}$ PASE is especially designed for older adults, and is the commonly used self-report measurement of PA, mainly dealing with frequency, duration, and intensity of different activities. ${ }^{24}$ It has been validated and found to be reliable in several studies in older population, ${ }^{25,26}$ and in patients with end-stage renal disease and knee pain. ${ }^{27,28}$

Recently, PASE has been translated into Chinese, and been confirmed to have acceptable reliability and validity in older Chinese population in Hong Kong..$^{29,30}$ PASE mainly comprises three components - leisure time (six questions), household (three questions), and work-related activities (one question) - which are relevant to patients with COPD.

To our knowledge, PASE has not been validated among Chinese patients aged 60 years or older with COPD. The aim of the this study was to assess the validity and reliability of the Chinese version of PASE (PASE-C) in patients with COPD, including test-retest reliability and measurement error, content validity, concurrent validity, criterion validity, and construct validity.

\section{Methods}

\section{Patients}

A double-center study was conducted in two tertiary hospitals in Tianjin, People's Republic of China. A total of 167 outpatients with COPD were recruited in this study from May 2015 to February 2016. The diagnosis of COPD was based on 2016 GOLD (Global Initiative for Chronic Obstructive Lung Disease) guidelines. ${ }^{31}$ Patients were eligible if they met the following criteria: 1) aged 60 years or older, 2) stable and having COPD with respiratory symptoms (dyspnea, cough, and sputum production) within normal day-to-day variation, and with no change in medication within the last four weeks, 3) able to understand and write Chinese, and 4) volunteering to participate and sign written informed consent. Exclusion criterion was having some disorders or progressive diseases (rheumatoid arthritis, cancer within the last five years, severe heart disease, severe osteoporosis, stroke, or multiple sclerosis), influencing daily life seriously.

\section{Procedure}

This study was approved by the Research Ethics Committee of the Tianjin Medical University. All outpatients were informed about the purpose and process of this study, and signed written informed consent was obtained from them. Participants completed a series of six instruments: demographic information, PASE-C and International Physical Activity Questionnaire-Short (IPAQ-S) to measure PA, SelfEfficacy for Managing Chronic Disease 6-Item Scale (SES6) to measure self-efficacy, Hospital Anxiety and Depression Scale (HADS) to measure mood status, and Medical Outcomes Study 36-Item Short Form Health Survey (SF-36) to measure health status. All participants completed these questionnaires at test session 1 , and 35 participants were randomly selected to carry pedometer for seven consecutive days, and they completed the PASE-C again after they returned the pedometer at test session 2. All participants received the same instructions from the same researcher, and participants 
who were selected to carry pedometer were asked to maintain their usual PA during the time period.

\section{Measures}

The demographic variables included age, gender, marital status, education level, career, employment status, salary, place of residence, smoking status, and drinking status. The clinical variable included body mass index, heart rate, grip strength $(\mathrm{kg})$, duration of COPD (months), comorbidities, grade of dyspnea (measured by the modified British Medical Research Council [mMRC] scale), frequency of exacerbation in the last year, forced expiratory volume in one second $\left(\mathrm{FEV}_{1}\right)$ as percentage of predicted $\left(\mathrm{FEV}_{1} \%\right.$ pred), and GOLD grade (according to GOLD 1 [mild]: $\mathrm{FEV}_{1} \geq 80 \%$ predicted, GOLD 2 [moderate]: $50 \% \leq \mathrm{FEV}_{1}<80 \%$ predicted, GOLD 3 [severe]: $30 \% \leq \mathrm{FEV}_{1}<50 \%$ predicted, GOLD 4 [very severe]: $\mathrm{FEV}_{1}<30 \%$ predicted). ${ }^{32}$

PASE, used to assess PA for the elderly was designed by Washburn et al. ${ }^{24}$ Vaughan and Miller translated the original English PASE into Chinese according to a forward-backward procedure. $^{30}$

The PASE-C comprises three components: leisure time, household, and work-related activities. Leisure time activities include sitting (L1), walking outside the home (L2), light activities (L3), moderate activities (L4), strenuous activities (L5), and muscle strength/endurance exercise (L6). Household activities include light housework (H7), heavy housework (H8) and home repairs, lawn work/yard care, outdoor gardening, and taking care of another person (H9). Work-related activities include paid or volunteer work (W10). The PASE-C scores were computed according to the weights of each activity and an equation, multiplying the amount of time spent (hours/day during the previous seven days) and participation (yes or no), which ranged from 0 to 500 or more. The PASE-C had acceptable reliability and validity in older Chinese population. ${ }^{30}$

Steps were tested by a pedometer (SP600; Shenzhenshi Sibowei Technology Co., Ltd, Shenzhen, People's Republic of China), which introduced the recent three-dimensional accelerometer transducer. The pedometer has a seven-day memory and records the total data, including the number of walking steps and energy expenditure per day. Patients carried the pedometers throughout the day, except while sleeping and bathing. The data for number of walking steps and energy expenditure for seven days were collected.

Grip strength was tested by a grip meter (WCS-100; Nantong Beisite Industry Co., Ltd, Jiangsu, People's Republic of China). When patients were in the standing position with their feet a foot apart and two arms in the natural prolapsed position, a grip meter was used to measure the grip strength of the dominant hand twice. The higher reading was chosen for analysis.

PA was evaluated by IPAQ-S which was designed to measure PA including walking, moderate activity, and vigorous activity during the previous seven days. ${ }^{33}$ Scores of the three levels of PA were calculated as frequencies and durations multiplied by known metabolic equivalent of task (MET): walking (3.3 METs), moderate activity (4.0 METs), and vigorous activity (8.0 METs). The scores of the three levels of PA were summed to obtain the total scores of IPAQ-S. IPAQ-S has been used among patients with COPD, ${ }^{34}$ and has acceptable convergent validity. ${ }^{35}$

Self-efficacy was evaluated by SES6 which was designed to assess perceived self-efficacy in patients with chronic diseases. ${ }^{36}$ It is a six-item scale with score of each item ranging from 1 to 10 , where 1 stands for no confidence and 10 stands for complete confidence. The total score is the average of the scores of the six items, which ranges from 1 to 10 , with higher scores representing greater perceived selfefficacy. ${ }^{36}$ SES6 has been used among patients with COPD, and the Cronbach's $\alpha$ was $0.97 .{ }^{37}$

Anxiety and depression were evaluated by HADS which was designed to measure mood disorders and identify the cases of anxiety and depression in patients with chronic diseases. ${ }^{38}$ This scale includes 14-item groups divided into two subscales, and odd numbers and even numbers are separately used to measure anxiety (HADS-A) and depression (HADS-D). For each subscale, the total score ranges from 0 to 21 . According to previous studies, anxiety or depression symptoms are classified in those patients who score 11 or more, borderline anxiety and depression symptoms are classified in those patients who score from 8 to 10 , and score lower than 7 indicates no clinically relevant symptoms. ${ }^{39,40}$ The HADS which has satisfactory reliability and validity ${ }^{41,42}$ has been widely used to assess anxiety and depression in patients with COPD. ${ }^{43,44}$

Quality of life was evaluated by SF-36 which includes eight subscales: physical functioning, role-physical, bodily pain, general health, vitality, social functioning, role-emotional, and mental health. ${ }^{45}$ The total scores of each subscale range from 0 to 100 , and higher scores indicate good health status. ${ }^{46}$ In addition, SF-36 has been validated in patients with COPD; for subscales of SF-36, the test-retest reliability was acceptable with the Cronbach's $\alpha$ ranging from 0.75 to $0.99,{ }^{47}$ and the construct validity against physician's evaluation of the patients' overall health status showed low-to-moderate correlations $(r=0.29-0.55){ }^{48}$ 


\section{Statistical analysis}

\section{Cross-cultural adaptations}

PASE-C has been obtained from Vaughan and Miller. ${ }^{30}$ A self-administered questionnaire is used in a new country or culture, and cross-cultural adaptations are essential to reach equivalence between original and target versions of the questionnaire. ${ }^{49}$ In different countries or cultures, a given PA may not be experienced, even if the PA is translatable, so the item would have to be replaced by a similar item that is experienced in the target culture, which is called experiential equivalence..$^{50}$ Based on that, PASE-C was not tested in the People's Republic of China, and PASE-C was required to achieve experiential equivalence to be adapted by the subjects of the People's Republic of China. Three experts whose major was PA with at least five years of experience in independently conducting experiential equivalence, cited that some PAs are popularized in the People's Republic of China according to the Compendium of Physical Activities, a coding scheme that classifies PA by energy expenditure. ${ }^{51}$ The expert committee made critical decisions about the target version of PASE-C. For activities of walking, walking to buy breakfast was added into the examples. For light activities of sport and recreation, tai chi and yangko dance forms were added into the examples. For moderate activities of sport and recreation, brisk walking and flying kites were added into the examples. For strenuous activities of sport and recreation, playing badminton, skiing, and square dance were added into the examples.

All statistical analyses were conducted using IBM SPSS version 19.0 (SPSS, Chicago, IL, USA). For descriptive data, continuous variables were expressed as mean \pm standard deviation (SD) or median (first to third quartiles, Q1-Q3) according to the Kolmogorov-Smirnov test, and categorical variables were expressed as relative frequencies and proportions. Significance level was set at a $P$-value of less than 0.05 .

\section{Reliability}

Reliability was tested by test-retest reliability and internal consistency. Test-retest reliability of the PASE-C was calculated using intraclass correlation coefficient (ICC) for absolute agreement between the PASE-C scores at test sessions 1 and 2. ICC scores greater than 0.75 indicated good reliability. ${ }^{52}$ Internal consistency of the scale was analyzed using Cronbach's coefficient $\alpha$.

\section{Measurement error}

In this research, measurement error was evaluated by the standard error of measurement (SEM), minimal detectable change (MDC), and limits of agreement (LoAs). SEM was calculated from the sample SD and the ICC of the scale according to the following formula:

$$
\mathrm{SEM}=\mathrm{SD} \sqrt{1-\mathrm{ICC}} . .^{53}
$$

MDC was calculated by the formula:

$$
\mathrm{MDC}=1.96 \times \sqrt{2} \times \mathrm{SEM}^{54}
$$

LoAs were evaluated through the visual judgment of the relationship between the PASE-C scores of each test and retest using the Bland-Altman plot, which was performed using MedCalc Software bvba (version 16.4.3). ${ }^{55}$

\section{Validity}

The validity of PASE-C was based on content validity, concurrent validity, criterion validity, and construct validity. The content validity index (CVI) was separately evaluated by six experts (including three nurses and three doctors) and four patients. The experts were experienced in COPD and were familiar with the PA for COPD, and they had at least 10 years of working experience. The patients with at least five years' history of COPD met the inclusion and exclusion criteria of this study. The Likert 4-point scale was used, where " 4 " indicated "very much relevance", " 3 " indicated "strong relevance", "2" indicated "weak relevance", and "1" indicated "no relevance". The CVI was reflexed by item-content validity index (I-CVI), scale-content validity index/universal agreement (S-CVI/UA), and scale-content validity index/average (S-CVI/Ave). The S-CVI/UA is the number of items scaled 3 or 4 divided by the total number of items, and the S-CVI/ Ave is the average of I-CVI of each item. ${ }^{56}$ The scale of $\mathrm{I}-\mathrm{CVI} \geq 0.78$ was considered acceptable, ${ }^{57}$ the $\mathrm{S}-\mathrm{CVI} / \mathrm{UA}>0.8$ showed good content validity, ${ }^{58}$ and the S-CVI/Ave was considered to overpass $0.9 .{ }^{59}$ Otherwise, experts were needed to provide explanation if they rated any item less than 3 . The following are the formulas used for calculations of CVI. ${ }^{56}$

$$
\begin{gathered}
\mathrm{I}-\mathrm{CVI}=\frac{\text { The number of experts rating } 3 \text { or } 4}{\text { The number of experts }} \\
P_{c}=\frac{n !^{*} 0.5^{n}}{A !(n-A) !} \\
K^{*}=\frac{\mathrm{I}-\mathrm{CVI}-P_{c}}{1-P_{c}}
\end{gathered}
$$

where $P_{\mathrm{c}}$ is the probability of random correlation coefficient and $K^{*}$ is the modified kappa coefficient and where $n$ is the 
number of experts, and $A$ is the number of experts who rated item 3 or 4 . Concurrent validity was tested by the correlation with IPAQ-S, criterion validity was tested by the correlations with walking steps and energy expenditure, and construct validity was tested by the correlations with SES6, HADS, SF-36, grip strength, and disease characteristics. Pearson correlation coefficients and Spearman correlation coefficients were used to assess concurrent validity, criterion validity, and construct validity, where $r>0.60$ represented high correlation, $r=0.30-0.60$ represented moderate correlation, and $r<0.30$ represented low correlation..$^{60} \mathrm{Based}$ on the previous studies, ${ }^{61,62}$ we hypothesized that PASE-C scores have high correlation with IPAQ-S scores and have moderate-to-high correlation with walking steps and energy expenditure. The PASE-C scores were hypothesized to have moderate correlation with SES6, HADS, SF-36, and grip strength. ${ }^{30,63}$ We thought that there were correlations between the disease characteristics and the PASE-C scores. ${ }^{64,65}$

\section{Results}

\section{Characteristics of participants}

A total of 167 outpatients with COPD were recruited in this study, with a mean age of 69.1 \pm 6.9 (range: 60-89) years. The demographic variables of patients with COPD are shown in Table 1, and the clinical variables are shown in Table 2. Among all, 35 outpatients completed the PASE-C twice and brought the pedometer with them for seven days.

\section{Reliability}

The PASE-C had an excellent seven-day test-retest reliability (ICC $=0.98,95 \%$ confidence interval: $0.96-0.99$ ) and an acceptable internal consistency (Cronbach's $\alpha=0.71$ ). For measurement error, the SEM and MDC values were 6.93 and 19.21, respectively. The Bland-Altman plot for the PASE-C score of test and retest is shown in Figure 1. The BlandAltman plot nearly showed equal distribution on both sides of the zero line, and the upper LoA was 19.0 and the lower LoA was -21.0 , of which two (6\%) were not inside the LoA.

\section{Validity}

The I-CVI values of the PASE-C items range from 0.70 to 1 . Except for the I-CVI values of L6, H9, and W10 items, the I-CVI values of other items of this scale were 1 . The S-CVI/ Ave and S-CVI/UA values were 0.93 and 0.70 , respectively. Table 3 shows each expert's ratings and calculation of CVI. For the lower I-CVI values of items, experts made some explanations. For L6 item, limited by the senility and disease, few patients had ability to do muscle strength/endurance
Table I Demographic variables of patients with COPD $(\mathrm{N}=167)$

\begin{tabular}{|c|c|c|}
\hline Variables & Number & Percent \\
\hline \multicolumn{3}{|l|}{ Gender } \\
\hline Female & 60 & 35.9 \\
\hline Male & 107 & 64.1 \\
\hline \multicolumn{3}{|l|}{ Marital status } \\
\hline Single & 9 & 5.4 \\
\hline Married & 158 & 94.6 \\
\hline \multicolumn{3}{|l|}{ Education level } \\
\hline Elementary or lower & 50 & 29.9 \\
\hline Junior high & 51 & 30.5 \\
\hline Senior high & 37 & 22.2 \\
\hline College or higher & 29 & 17.4 \\
\hline \multicolumn{3}{|l|}{ Career } \\
\hline Worker & 110 & 65.9 \\
\hline Nonworker & 57 & 34.1 \\
\hline \multicolumn{3}{|l|}{ Employment status } \\
\hline Employed & 18 & 10.8 \\
\hline Unemployed & 149 & 89.2 \\
\hline \multicolumn{3}{|l|}{ Salary (Yuan/month) } \\
\hline$\leq 500$ & 22 & 13.2 \\
\hline $50 I-I, 500$ & 15 & 9.0 \\
\hline $1,501-3,000$ & 65 & 38.9 \\
\hline$\geq 3,00 \mathrm{I}$ & 65 & 38.9 \\
\hline \multicolumn{3}{|l|}{ Place of residence } \\
\hline Countryside & 33 & 19.8 \\
\hline City & 134 & 80.2 \\
\hline \multicolumn{3}{|l|}{ Smoking status } \\
\hline Never & 57 & 34.1 \\
\hline Ex-smoking & 80 & 47.9 \\
\hline Smoking & 30 & 18.0 \\
\hline \multicolumn{3}{|l|}{ Drinking status } \\
\hline Never & 75 & 44.9 \\
\hline Ex-drinking & 50 & 29.9 \\
\hline Drinking & 42 & 25.2 \\
\hline \multicolumn{3}{|l|}{ Comorbidities } \\
\hline Hypertension & 47 & 28.1 \\
\hline Asthma & 34 & 20.4 \\
\hline Pulmonary heart disease & 33 & 19.8 \\
\hline Coronary heart disease & 27 & 16.2 \\
\hline Bronchiectasis & 16 & 9.6 \\
\hline Diabetes & 19 & 11.4 \\
\hline Others & 4 & 2.4 \\
\hline
\end{tabular}

exercise. For H9 item, home repair was a careful and timeconsuming activity, which required some experts, and most patients lived in flat without garden, so they had little chance to do these activities. For W10 item, based on the Chinese work system, most people would retire when they are 60 years old, and volunteering is not popular in the People's Republic of China, so work- or volunteer-related activities had little association with PA of patients aged 60 years or older with COPD. However, in order to ensure the popularity of PASE-C among those aged less than 60 years, we did not delete these items. 
Table 2 Clinical variables of patients with COPD $(\mathrm{N}=167)$

\begin{tabular}{|c|c|c|c|}
\hline Variables & Number (percent) & Mean (SD)/median (QI-Q3) & Range \\
\hline BMI $\left(\mathrm{kg} / \mathrm{m}^{2}\right)$ & 167 & $23.98(4.08)$ & |4.87-36.89 \\
\hline Heart rate (bpm) & 167 & $77(70-84)$ & $53-120$ \\
\hline Duration of COPD (months) & 167 & $60(36-90)$ & $3-240$ \\
\hline mMRC scale & 167 & $I(I-2)$ & $0-4$ \\
\hline Frequency (in the last year) & 167 & $I(I-2)$ & $0-5$ \\
\hline $\mathrm{FEV}_{1} \%$ pred & 167 & $48.40(18.75)$ & $9.40-98.00$ \\
\hline \multicolumn{4}{|l|}{ GOLD grade } \\
\hline I & $12(7.2)$ & & \\
\hline 2 & $61(36.5)$ & & \\
\hline 3 & $60(35.9)$ & & \\
\hline 4 & $34(20.4)$ & & \\
\hline Grip strength (kg) & 167 & $24.6(9.2)$ & $1.6-54.5$ \\
\hline PASE-C scores & 167 & $73.25(49.47)$ & $0-246.82$ \\
\hline Males & 107 & $72.29(49.64)$ & $0-195.80$ \\
\hline Females & 60 & $74.95(49.55)$ & $0-246.82$ \\
\hline IPAQ scores (MET-min) & 167 & $23.30(10.00-36.57)$ & $0-208.00$ \\
\hline SES6 scores & 167 & $7.50(5.67-8.33)$ & $1.83-10.00$ \\
\hline Total scores of HADS & 167 & $7(3-12)$ & $0-34$ \\
\hline HADS-A & & $2(0-5)$ & $0-18$ \\
\hline HADS-D & & $4(2-7)$ & $0-19$ \\
\hline SF-36 & 167 & & \\
\hline PF & & $75.00(50.00-90.00)$ & $0-100$ \\
\hline RP & & $50.00(0-100.00)$ & $0-100$ \\
\hline RE & & $100.00(33.33-100.00)$ & $0-100$ \\
\hline $\mathrm{BP}$ & & $100.00(74.00-100.00)$ & $12-100$ \\
\hline VT & & $70.00(50.00-75.00)$ & $15-90$ \\
\hline $\mathrm{SF}$ & & $77.78(55.56-100.00)$ & $0-100$ \\
\hline $\mathrm{MH}$ & & $76.00(64.00-84.00)$ & $20-100$ \\
\hline $\mathrm{GH}$ & & $45.00(30.00-62.00)$ & $0-92$ \\
\hline Walking steps & 35 & $23,788(13,545-34,872)$ & $3,000-58,69 \mid$ \\
\hline Energy expenditure (kcal/weight) & 35 & $980.6(464.8-1,522.0)$ & $105.0-3,387.3$ \\
\hline
\end{tabular}

Abbreviations: SD, standard deviation; Q, quartile; bpm, beats per minute; BMI, body mass index; mMRC, modified British Medical Research Council; FEV \% pred, forced expiratory volume in one second as percentage of predicted; GOLD, Global Initiative for Chronic Obstructive Lung Disease; PASE-C, Chinese version of Physical Activity Scale for the Elderly; IPAQ, International Physical Activity Questionnaire; MET, metabolic equivalent of task; SES6, Self-Efficacy for Managing Chronic Disease 6-Item Scale; HADS, Hospital Anxiety and Depression Scale; HADS-A, HADS for Anxiety; HADS-D, HADS for Depression; SF-36, Medical Outcomes Study 36-Item Short Form Health Survey; PF, physical functioning; RP, role-physical; RE, role-emotional; BP, bodily pain; VT, vitality; SF, social functioning; $M H$, mental health; GH, general health.

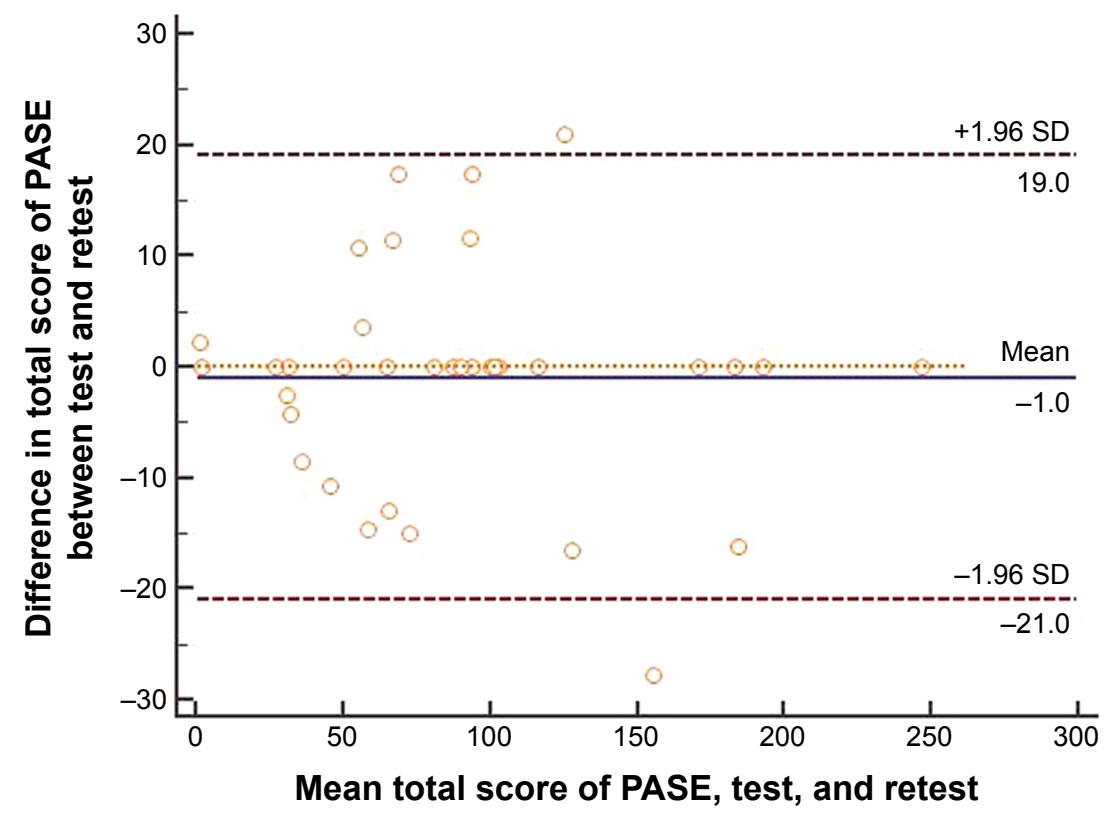

Figure I Bland-Altman plot for total score of PASE.

Notes: The central horizontal line represents the mean difference, the flanking lines represent the $95 \%$ limits of agreement, and the dotted line represents that there is no difference between the total score of PASE, test, and retest.

Abbreviations: SD, standard deviation; PASE, Physical Activity Scale for the Elderly. 
Table 3 Each expert's rating and calculation of CVI

\begin{tabular}{|c|c|c|c|c|c|c|c|c|c|c|c|c|c|c|c|}
\hline \multirow[t]{2}{*}{ Item } & \multicolumn{10}{|c|}{ Expert rating } & \multirow{2}{*}{$\begin{array}{l}\text { Number of three } \\
\text { or four items }\end{array}$} & \multirow[t]{2}{*}{ I-CVI } & \multirow[t]{2}{*}{$P_{c}$} & \multirow[t]{2}{*}{$K^{*}$} & \multirow[t]{2}{*}{ Evaluation } \\
\hline & $\mathbf{A}$ & B & C & D & $\mathbf{E}$ & $\mathbf{F}$ & $\mathbf{G}$ & $\mathbf{H}$ & $\mathbf{I}$ & J & & & & & \\
\hline$\overline{\mathrm{LI}}$ & 4 & 4 & 4 & 4 & 4 & 4 & 4 & 4 & 4 & 4 & 10 & 1 & 0.001 & 1 & Excellent \\
\hline L2 & 4 & 4 & 4 & 4 & 4 & 4 & 4 & 4 & 4 & 4 & 10 & 1 & 0.001 & 1 & Excellent \\
\hline L3 & 4 & 4 & 4 & 3 & 4 & 3 & 4 & 4 & 4 & 4 & 10 & 1 & 0.001 & 1 & Excellent \\
\hline L4 & 3 & 4 & 4 & 3 & 4 & 3 & 4 & 4 & 4 & 4 & 10 & 1 & 0.001 & 1 & Excellent \\
\hline L5 & 3 & 3 & 4 & 3 & 3 & 3 & 4 & 4 & 4 & 4 & 10 & 1 & 0.001 & 1 & Excellent \\
\hline L6 & 3 & 3 & 3 & 3 & 2 & 3 & 4 & 2 & 3 & 3 & 8 & 0.80 & 0.044 & 0.79 & Excellent \\
\hline $\mathrm{H} 7$ & 4 & 4 & 4 & 4 & 4 & 4 & 4 & 4 & 4 & 4 & 10 & I & 0.001 & 1 & Excellent \\
\hline $\mathrm{H} 8$ & 4 & 4 & 4 & 4 & 3 & 4 & 4 & 4 & 4 & 4 & 10 & I & 0.001 & 1 & Excellent \\
\hline $\mathrm{H} 9$ & 2 & 4 & 3 & 3 & 2 & 3 & 3 & 2 & 4 & 3 & 7 & 0.70 & 0.117 & 0.66 & Good \\
\hline WIO & 3 & 4 & 3 & 2 & 2 & 3 & 3 & 3 & 4 & 3 & 8 & 0.80 & 0.044 & 0.79 & Excellent \\
\hline
\end{tabular}

Notes: According to the criteria for $K^{*},>0.74$ is considered excellent, $0.60-0.74$ good, and $0.40-0.59$ fair. $P_{c}$, probability of random correlation coefficient; $K^{*}$, modified kappa coefficient.

Abbreviations: CVI, content validity index; I-CVI, item-content validity index.

For concurrent validity, PASE-C scores had correlation with IPAQ-S scores $(r=0.651, P<0.01)$. Criterion validity was confirmed by correlation with the walking steps $(r=0.611$, $P<0.01)$ and energy expenditure $(r=0.493, P<0.01)$. For construct validity, PASE-C scores had correlations with SES6 scores $(r=0.396, P<0.01)$, HADS-D scores $(r=-0.234$, $P<0.01)$, and seven subscales of SF-36 $(r=0.182-0.525$, $P<0.01)$. In addition, the PASE-C scores had associations with grip strength $(r=0.341, P<0.01)$, duration of COPD $(r=-0.215, P<0.01)$, mMRC scale $(r=-0.354, P<0.01)$, $\mathrm{FEV}_{1} \%$ pred $(r=0.307, P<0.01)$, and GOLD grade $(r=-0.264$, $P<0.01)$. Table 4 shows the correlations between the PASE-C scores and clinical variables.

\section{Discussion}

For patients with COPD, physical inactivity is common compared to age-matched controls, and physical inactivity would worsen disease progression. ${ }^{66}$ Physical inactivity can predict the worse outcome of COPD, and has association with mortality and rate of hospital admission. ${ }^{17}$ Therefore, assessing and increasing PA are becoming increasingly important. The aim of this study was to evaluate PA in patients with COPD using the well-validated PASE-C. To our knowledge, this is the first study in which the psychometric properties of the PASE-C were tested in Chinese patients with COPD. The reliability and validity results showed that the PASE-C was a simple and useful tool to measure the PA of patients aged 60 years or older with COPD in the People's Republic of China.

In this study, the PASE-C scores were 73.25 \pm 49.47 , which showed that the PA of patients aged 60 years or older with COPD was worse than that of general older people in the People's Republic of China $(t=5.069, P<0.001){ }^{29}$

The ICC of PASE-C was 0.98 , indicating that it had an excellent retest reliability. ${ }^{52}$
The ICC was superior to the previous studies on elderly, which involved mail $(r=0.84)$ and telephone samples $(r=0.68)$ in the original study, ${ }^{24}$ and ICC was 0.65 in the Japanese translation study by Hagiwara et $\mathrm{al}^{26}$ and 0.79 in the Chinese

Table 4 Correlations between the PASE-C scores and clinical variables

\begin{tabular}{lll}
\hline Variables & $\boldsymbol{r}$ & $\boldsymbol{P}$-value \\
\hline Age (years) & $-0.23 \mathrm{I}$ & 0.003 \\
BMI (kg/m²) & 0.025 & 0.749 \\
Heart rate (bpm) & -0.040 & 0.609 \\
Duration of COPD (months) & -0.215 & 0.005 \\
mMRC scale & -0.354 & 0.000 \\
FEV \% pred & 0.307 & 0.000 \\
GOLD grade & -0.264 & 0.001 \\
Walking steps & 0.611 & 0.000 \\
Energy expenditure (kcal/weight) & 0.493 & 0.003 \\
Grip strength (kg) & 0.341 & 0.000 \\
IPAQ & 0.651 & 0.000 \\
SES6 & 0.396 & 0.000 \\
HADS & & \\
HADS-A & -0.149 & 0.055 \\
HADS-D & -0.234 & 0.002 \\
SF-36 & & \\
PF & 0.525 & 0.000 \\
RP & 0.218 & 0.005 \\
RE & 0.182 & 0.019 \\
BP & 0.030 & 0.699 \\
VT & 0.491 & 0.000 \\
SF & 0.475 & 0.000 \\
MH & 0.246 & 0.001 \\
GH & 0.443 & 0.000 \\
\hline Abbrevitions PASE-C, Chis & \\
\hline
\end{tabular}

Abbreviations: PASE-C, Chinese version of Physical Activity Scale for the Elderly; BMI, body mass index; mMRC, modified British Medical Research Council; FEV \% pred, forced expiratory volume in one second as percentage of predicted; GOLD, Global Initiative for Chronic Obstructive Lung Disease; IPAQ, International Physical Activity Questionnaire; SES6, Self-Efficacy for Managing Chronic Disease 6-Item Scale; HADS, Hospital Anxiety and Depression Scale; HADS-A, HADS for Anxiety; HADS-D, HADS for Depression; SF-36, Medical Outcomes Study 36-Item Short Form Health Survey; PF, physical functioning; RP, role-physical; RE, roleemotional; BP, bodily pain; VT, vitality; SF, social functioning; $\mathrm{MH}$, mental health; $\mathrm{GH}$, general health. 
translation study by Vaughan and Miller. ${ }^{30}$ A Cronbach's coefficient $\alpha$ greater than 0.7 is usually considered indicative of a reliable scale. ${ }^{67}$ So, our results confirmed that the PASE-C has an acceptable internal consistency.

Two patients were not inside the LoA on the BlandAltman plot which showed that there was a reporting bias. One of the outliers reported his PA decreased due to the weather, while the other explained that he should take care of his wife who was admitted to hospital recently, which led to increase in his PA. These conditions could explain the difference between test and retest. Thus, in this study, the bias between test and retest was minimal. With high ICC value, there were little measurement error and narrow LoA, and so we consider that the reliability of PASE-C is excellent.

In this study, the PASE-C showed good content validity. As a criterion, the $\mathrm{I}-\mathrm{CVI} \geq 0.78$ indicated that the item has an acceptable content validity. ${ }^{57}$ However, the I-CVI of H9 was 0.70 ; hence, it is essential to make further modification. As in our previous hypothesis, concurrent validity was satisfactory due to PASE scores having high correlation with IPAQ-S scores, and criterion validity was acceptable due to PASE-C scores having high correlation with walking steps and moderate correlation with energy expenditure. For the construct validity, there were correlations between the PASE-C scores and SES6 scores, HADS-D scores, most of the subscales scores of SF-36, and disease characteristics, which mainly confirmed our previous hypotheses. So, the PASE-C showed satisfactory construct validity.

\section{Limitations}

Although the results indicated that the PASE-C is suitable to assess the population in this study, there are several limitations that need to be addressed. First of all, the original PASE was designed for elderly aged 65 years or older in developed countries, but in the People's Republic of China, the elderly are defined as people aged 60 years or older. In this study, the participants were aged 60 years or older, which would influence the generalization in the world. Second, PASE-C scores had low correlations with HADS-D scores and some subscales scores of SF-36, which may be because HADS and SF-36 are not specific to patients with COPD, and it is essential to select more specific questionnaires in future study. Third, pedometer may underestimate or overestimate PA, so in order to test the validity of PASE more accurately, future study could use GOLD standard measures of PA as the criterion validity.

\section{Conclusion}

The PASE-C has shown acceptable psychometric properties for assessing the PA in patients aged 60 years or older with
COPD. Therefore, it is a good method to evaluate PA in patients with COPD, and it can be popularized in the future based on its convenience and effectiveness.

\section{Acknowledgments}

The authors are grateful for the financial support from the Humanities and Social Science Research of China (Grant No 15YJA2H109), and thank William C. Miller, $\mathrm{PhD}$, for providing the Chinese version of PASE for free. The authors express their appreciation to the staff and outpatients of the respiratory care unit of Tianjin First Center Hospital and Tianjin Chest Hospital for their support in data collection.

\section{Author contributions}

All authors contributed to the conception, design, collection and analysis of data, as well as in the creation and critical review of the manuscript. All authors provided approval of the final manuscript.

\section{Disclosure}

The authors report no conflicts of interest in this work.

\section{References}

1. Nelson ME, Rejeski WJ, Blair SN, et al; American College of Sports Medicine; American Heart Association. Physical activity and public health in older adults: recommendation from the American College of Sports Medicine and the American Heart Association. Circulation. 2007;116(9):1094-1105.

2. Warburton DE, Nicol CW, Bredin SS. Health benefits of physical activity: the evidence. CMAJ. 2006;174(6):801-809.

3. Troosters T, Sciurba F, Battaglia S, et al. Physical inactivity in patients with COPD, a controlled multi-center pilot-study. Respir Med. 2010;104(7):1005-1011.

4. Byrom B, Rowe DA. Measuring free-living physical activity in COPD patients: deriving methodology standards for clinical trials through a review of research studies. Contemp Clin Trials. 2016;47: $172-184$

5. Watz H, Waschki B, Boehme C, Claussen M, Meyer T, Magnussen H. Extrapulmonary effects of chronic obstructive pulmonary disease on physical activity: a cross-sectional study. Am J Respir Crit Care Med. 2008;177(7):743-751.

6. Watz H, Waschki B, Meyer T, Magnussen H. Physical activity in patients with COPD. Eur Respir J. 2009;33(2):262-272.

7. Celli BR, MacNee W; ATS/ERS Task Force. Standards for the diagnosis and treatment of patients with COPD: a summary of the ATS/ ERS position paper. Eur Respir J. 2004;23(6):932-946.

8. Rabe KF, Hurd S, Anzueto A, et al; Global Initiative for Chronic Obstructive Lung Disease. Global strategy for the diagnosis, management, and prevention of chronic obstructive pulmonary disease: GOLD executive summary. Am J Respir Crit Care Med. 2007;176(6): 532-555.

9. Nici L, Donner C, Wouters E, et al; ATS/ERS Pulmonary Rehabilitation Writing Committee. American Thoracic Society/European Respiratory Society statement on pulmonary rehabilitation. Am J Respir Crit Care Med. 2006;173(12):1390-1413.

10. Booth FW, Gordon SE, Carlson CJ, Hamilton MT. Waging war on modern chronic diseases: primary prevention through exercise biology. J Appl Physiol (1985). 2000;88(2):774-787. 
11. Garcia-Aymerich J, Lange P, Benet M, Schnohr P, Antó JM. Regular physical activity reduces hospital admission and mortality in chronic obstructive pulmonary disease: a population based cohort study. Thorax. 2006;61(9):772-778.

12. Garcia-Aymerich J, Lange P, Benet M, Schnohr P, Antó JM. Regular physical activity modifies smoking-related lung function decline and reduces risk of chronic obstructive pulmonary disease: a population-based cohort study. Am J Respir Crit Care Med. 2007;175(5):458-463.

13. Nici L, Lareau S, ZuWallack R. Pulmonary rehabilitation in the treatment of chronic obstructive pulmonary disease. Am Fam Physician. 2010;82(6):655-660.

14. Rochester CL, Vogiatzis I, Holland AE, et al; ATS/ERS Task Force on Policy in Pulmonary Rehabilitation. American Thoracic Society/ European Respiratory Society statement on pulmonary rehabilitation. Am J Respir Crit Care Med. 2015;192(11):1373-1386.

15. Bentsen SB, Wentzel-Larsen T, Henriksen AH, Rokne B, Wahl AK. Self-efficacy as a predictor of improvement in health status and overall quality of life in pulmonary rehabilitation - an exploratory study. Patient Educ Couns. 2010;81(1):5-13.

16. Gill DL, Hammond CC, Reifsteck EJ, et al. Physical activity and quality of life. J Prev Med Public Health. 2013;46(Suppl 1):S28-S34.

17. Gimeno-Santos, Frei A, Steurer-Stey C, et al; PROactive consortium. Determinants and outcomes of physical activity in patients with COPD: a systematic review. Thorax. 2014;69(8):731-739.

18. Hartman JE, Boezen HM, Zuidema MJ, de Greef MH, Ten Hacken NH. Physical activity recommendations in patients with chronic obstructive pulmonary disease. Respiration. 2014;88(2):92-100.

19. Araújo A. COPD and physical activity. Rev Port Pneumol (2006). 2016; 22(5):299-301.

20. Helmerhorst HJ, Brage S, Warren J, Besson H, Ekelund U. A systematic review of reliability and objective criterion-related validity of physical activity questionnaires. Int J Behav Nutr Phys Act. 2012;9:103.

21. Munguía-Izquierdo D, Legaz-Arrese A, Mannerkorpi K. Transcultural adaptation and psychometric properties of a Spanish-language version of physical activity instruments for patients with fibromyalgia. Arch Phys Med Rehabil. 2011;92(2):284-294.

22. Ainsworth BE. How do I measure physical activity in my patients? Questionnaires and objective methods. Br J Sports Med. 2009;43:6-9.

23. Terwee CB, MokkinkLB, van Poppel MN, Chinapaw MJ, van Mechelen W, de Vet HC. Qualitative attributes and measurement properties of physical activity questionnaires: a checklist. Sports Med. 2010;40(7): 525-537.

24. Washburn RA, Smith KW, Jette AM, Janney CA. The physical activity scale for the elderly (PASE): development and evaluation. J Clin Epidemiol. 1993;46(2):153-162.

25. Dinger MK, Oman RF, Taylor EL, Vesely SK, Able J. Stability and convergent validity of the Physical Activity Scale for the Elderly (PASE). J Sports Med Phys Fitness. 2004;44(2):186-192.

26. Hagiwara A, Ito N, Sawai K, Kazuma K. Validity and reliability of the Physical Activity Scale for the Elderly (PASE) in Japanese elderly people. Geriatr Gerontol Int. 2008;8(3):143-151.

27. Johansen KL, Painter P, Kent-Braun JA, et al. Validation of questionnaires to estimate physical activity and functioning in end-stage renal disease. Kidney Int. 2001;59(3):1121-1127.

28. Dunlop DD, Song J, Semanik PA, Sharma L, Chang RW. Physical activity levels and functional performance in the osteoarthritis initiative: a graded relationship. Arthritis Rheum. 2011;63(1):127-163.

29. Ngai SP, Cheung RT, Lam PL, Chiu JK, Fung EY. Validation and reliability of the Physical Activity Scale for the Elderly in Chinese population. J Rehabil Med. 2012;44(5):462-465.

30. Vaughan K, Miller WC. Validity and reliability of the Chinese translation of the physical activity scale for the elderly (PASE). Disabil Rehabil. 2013;35(3):191-197.

31. Global Initiative for Chronic Obstructive Lung Disease. Global strategy for the diagnosis, management, and prevention of chronic obstructive pulmonary disease - updated 2016. Available from: http://goldcopd. org/global-strategy-diagnosis-management-prevention-copd-2016. Accessed July 20, 2016.
32. Vestbo J, Hurd SS, Agustí AG, et al. Global strategy for the diagnosis, management, and prevention of chronic obstructive pulmonary disease: GOLD executive summary. Am J Respir Crit Care Med. 2013;187(4): 347-365.

33. Craig CL, Marshall AL, Sjöström M, et al. International physical activity questionnaire: 12-country reliability and validity. Med Sci Sports Exerc. 2003;35(8):1381-1395.

34. Hirayama F, Lee AH, Binns CW, Leong CC, Hiramatsu T. Physical activity of patients with chronic obstructive pulmonary disease: implications for pulmonary rehabilitation. J Cardiopulm Rehabil Prev. 2008;28(5):330-334.

35. Tödt K, Skargren E, Jakobsson P, Theander K, Unosson M. Factors associated with low physical activity in patients with chronic obstructive pulmonary disease: a cross-sectional study. Scand J Caring Sci. 2015; 29(4):697-707.

36. Lorig K, Stewart A, Ritter P, González V, Laurent D, Lynch J. Outcome Measures for Health Education and Other Health Care Interventions. Thousand Oaks, CA: Sage Publications; 1996.

37. Stellefson M, Chaney BH, Chaney JD. Examining the efficacy of DVD technology compared to print-based material in COPD self-management education of rural patients. Calif J Health Promot. 2009;7(2): 26-42.

38. Zigmond AS, Snaith RP. The Hospital Anxiety and Depression Scale. Acta Psychiatr Scand. 1983;67(6):361-370.

39. Krebber AM, Buffart LM, Kleijn G, et al. Prevalence of depression in cancer patients: a meta-analysis of diagnostic interviews and self-report instruments. Psychooncology. 2014;23(2):121-130.

40. Olssøn I, Mykletun A, Dahl AA. The Hospital Anxiety and Depression Rating Scale: a cross-sectional study of psychometrics and case finding abilities in general practice. BMC Psychiatry. 2005;5:46.

41. Johnston M, Pollard B, Hennessey P. Construct validation of Hospital Anxiety and Depression Scale with clinical populations. J Psychosom Res. 2000;48(6):579-584.

42. Mykletun A, Stordal E, Dahl AA. Hospital Anxiety and Depression (HAD) scale: factor structure, item analyses and internal consistency in a large population. Br J Psychiatry. 2001;179:540-544.

43. Trappenburg JC, Troosters T, Spruit MA, Vandebrouck N, Decramer M, Gosselink R. Psychosocial conditions do not affect short-term outcome of multidisciplinary rehabilitation in chronic obstructive pulmonary disease. Arch Phys Med Rehabil. 2005;86:1788-1792.

44. Bentsen SB, Rokne B, Wentzel-Larsen T, Hentiksen AH, Wahl AK. The Norwegian version of the chronic obstructive pulmonary disease self-efficacy scale (CSES): a validation and reliability study. Scand J Caring Sci. 2010;24(3):600-609.

45. Stewart AL, Ware JE, editors. Measuring Functioning and Well-Being: The Medical Outcome Study Approach. Durham, NC: Duke University Press; 1992.

46. Ware JE, Snow KK. SF-36 Health Survey Manual and Interpretation Guide. Boston, MA: The Health Institute, New England Medical Center; 1993.

47. Harper R, Brazier JE, Waterhouse JC, Walters SJ, Jones NM, Howard P. Comparison of outcome measures for patients with chronic obstructive pulmonary disease (COPD) in an outpatient setting. Thorax. 1997; 52(10):879-887.

48. Bendtsen P, Leijon M, Sommer AS, Kristenson M. Measuring healthrelated quality of life in patients with chronic obstructive pulmonary disease in a routine hospital setting: feasibility and perceived value. Health Qual Life Outcomes. 2003;1:5.

49. Beaton DE, Bombardier C, Guillemin F, Ferraz MB. Guidelines for the process of cross-cultural adaptation of self-report measures. Spine (Phila Pa 1976). 2000;25(24):3186-3191.

50. Guillemin F, Bombardier C, Beaton D. Cross-cultural adaptation of health-related quality of life measures: literature review and proposed guidelines. J Clin Epidemiol. 1993;46(12):1417-1432.

51. Ainsworth BE, Haskell WL, Whitt MC, et al. Compendium of physical activities: an update of activity codes and MET intensities. Med Sci Sports Exerc. 2000;32(9 Supp1):S498-S504. 
52. Marx RG, Menezes A, Horovitz L, Jones EC, Warren RF. A comparison of two time intervals for test-retest reliability of health status instruments. J Clin Epidemiol. 2003;56(8):730-735.

53. Atkinson G, Nevill AM. Statistical methods for assessing measurement error (reliability) in variables relevant to sports medicine. Sports Med. 1998;26(4):217-238.

54. Terwee CB, Bot SD, de Boer MR, et al. Quality criteria were proposed for measurement properties of health status questionnaires. J Clin Epidemiol. 2007;60(1):34-42.

55. Bland JM, Altman DG. Measuring agreement in method comparison studies. Stat Methods Med Res. 1999;8(2):135-160.

56. Polit DF, Beck CT, Owen SV. Is the CVI an acceptable indicator of content validity? Appraisal and recommendations. Res Nurs Health. 2007;30(4): 459-467.

57. Lynn MR. Determination and quantification of content validity. Nurs Res. 1986;35(6):382-385.

58. Davis LL. Instrument review: getting the most from your panel of experts. Appl Nurs Res. 1992;5(4):194-197.

59. Waltz CF, Strickland OL, Lenz ER. Measurement in Nursing and Health Research. 3rd ed. New York, NY: Springer; 2005.

60. Streiner DL, Norman GR. Health Measurement Scales: A Practical Guide to Their Development and Use. Oxford: Oxford University Press; 2003.

61. Svege I, Kolle E, Risberg MA. Reliability and validity of the Physical Activity Scale for the Elderly (PASE) in patients with hip osteoarthritis. BMC Musculoskelet Disord. 2012;13:26.

62. Thompson PD, Buchner D, Pina IL, et al; American Heart Association Council on Clinical Cardiology Subcommittee on Exercise, Rehabilitation, and Prevention; American Heart Association Council on Nutrition, Physical Activity, and Metabolism Subcommittee on Physical Activity. Exercise and physical activity in the prevention and treatment of atherosclerotic cardiovascular disease: a statement from the Council on Clinical Cardiology (Subcommittee on Exercise, Rehabilitation, and Prevention) and the Council on Nutrition, Physical Activity, and Metabolism (Subcommittee on Physical Activity). Circulation. 2003; 107(24):3109-3116.
63. Schüz N, Walters JA, Cameron-Tucker H, Scott J, Wood-Baker R, Walters EH. Patient anxiety and depression moderate the effects of increased self-management knowledge on physical activity: a secondary analysis of a randomised controlled trial on health-mentoring in COPD. COPD. 2015;12(5):502-509.

64. Garcia-Aymerich J, Félez MA, Escarrabill J, et al. Physical activity and its determinants in severe chronic obstructive pulmonary disease. Med Sci Sports Exerc. 2004;36(10):1667-1673.

65. DePew ZS, Garofoli AC, Novotny PJ, Benzo RP. Screening for severe physical inactivity in chronic obstructive pulmonary disease: the value of simple measures and the validation of two physical activity questionnaires. Chron Respir Dis. 2013;10(1):19-27.

66. Watz H, Pitta F, Rochester CL, et al. An official European Respiratory Society statement on physical activity in COPD. Eur Respir J. 2014; 44(6):1521-1537.

67. Streiner DL. Starting at the beginning: an introduction to coefficient alpha and internal consistency. J Pers Assess. 2003;80(1):99-103.
International Journal of COPD

\section{Publish your work in this journal}

The International Journal of COPD is an international, peer-reviewed journal of therapeutics and pharmacology focusing on concise rapid reporting of clinical studies and reviews in COPD. Special focus is given to the pathophysiological processes underlying the disease, intervention programs, patient focused education, and self management protocols.

\section{Dovepress}

This journal is indexed on PubMed Central, MedLine and CAS. The manuscript management system is completely online and includes a very quick and fair peer-review system, which is all easy to use. Visit http://www.dovepress.com/testimonials.php to read real quotes from published authors. 